\title{
Assessing narcolepsy with cataplexy in children and adolescents: development of a cataplexy diary and the ESS-CHAD
}

This article was published in the following Dove Press journal:

Nature and Science of Sleep

14 August 2017

Number of times this article has been viewed

\author{
Y Grace Wang' \\ Khadra Benmedjahed ${ }^{2}$ \\ Jérémy Lambert ${ }^{2}$ \\ Christopher J Evans ${ }^{3}$ \\ Steve Hwang ${ }^{3}$ \\ Jed Black ${ }^{1,4}$ \\ Murray W Johns ${ }^{5}$ \\ 'Clinical Development, Jazz \\ Pharmaceuticals, Palo Alto, CA, USA; \\ ${ }^{2}$ Patient-Centered Outcomes, Mapi, \\ Lyon, France; ${ }^{3}$ Endpoint Outcomes, \\ Boston, MA, USA; ${ }^{4}$ Sleep Medicine, \\ Stanford Sleep Medicine Center, \\ Redwood City, CA, USA; ${ }^{5}$ Epworth \\ Sleep Centre, East Melbourne, VIC, \\ Australia
}

Objective: The aim of this study was to qualitatively evaluate concepts for incorporation into a daily diary to capture cataplexy frequency and to assess the content validity of the Epworth Sleepiness Scale for Children and Adolescents (ESS-CHAD) in pediatric patients with narcolepsy.

Patients and methods: Face-to-face concept elicitation and cognitive interviews were conducted with children ( $7-9$ years; $n=13$ ) and adolescents $(10-17$ years; $n=16)$ who have narcolepsy with cataplexy, and their parents/caregivers.

Results: Similarities and differences were noted between narcolepsy concepts described by children and their parents/caregivers, suggesting some different but complementary perspectives; parents may not recognize cataplexy symptoms/triggers as well as children, but parents have greater recognition of the circumstances of falling asleep. Cataplexy diary modifications included changes in definitions and examples of cataplexy, using child-friendly terminology, adding a quantitative question to determine daily frequency, and standardizing the questionnaire for evening administration with self-completion by the child. Modifications were made to ESSCHAD for child-friendly wording and to ensure that items reflect activities (eating, watching TV/ video) and environments (school, bus/car transport) in which children are likely to participate. Two ESS-CHAD versions were proposed: one with a 1-month recall period, for general use, and the other with a recall period of "since your last study visit," for research, which could be shorter or longer than 1 month (as short as 1 week).

Conclusion: The cataplexy diary and ESS-CHAD were modified for the assessment of children and adolescents. Further psychometric validation is recommended. These measures are being used in a Phase III, placebo-controlled clinical trial of sodium oxybate in children and adolescents with narcolepsy.

Keywords: narcolepsy, cataplexy, sleepiness, assessment, children, adolescents

\section{Introduction}

Narcolepsy symptom onset generally occurs during childhood or adolescence. ${ }^{1-3}$ However, diagnosis is often delayed due to lack of symptom recognition. ${ }^{4,5}$ Such a delay may have a profound impact because pediatric narcolepsy is associated with impaired academic performance and reduction in social and participatory activities. ${ }^{3}$

Excessive daytime sleepiness (EDS) and cataplexy are considered the cardinal symptoms of narcolepsy. Although cataplexy (transient episodes of muscle weakness or paralysis) is considered confirmatory for a diagnosis of narcolepsy type 1, it is present in approximately $70 \%$ of patients. ${ }^{6,7}$ In contrast, EDS is present in all patients with narcolepsy type 1 and type 2 and is required for a diagnosis.
Correspondence: Y Grace Wang Jazz Pharmaceuticals, 3180 Porter Drive, Palo Alto, CA 94304, USA

Tel +l 6504962687

Fax + I 650496287 |

Email grace.wang@jazzpharma.com 
Several differences in presentation have been noted between pediatric and adult narcolepsy patients. In studies of pediatric narcolepsy with cataplexy, disease onset is characterized by an abrupt increase of total sleep in 24 hours, as well as by complex movements that can include partial eyelid droop, variable mouth opening, frequent tongue protrusion, or repeated gait unsteadiness, and facial and masticatory muscle contractions. ${ }^{8,9}$ The hypotonic phenomena and abnormal facial movements may decrease over time and evolve into a more classic cataplexy presentation, while total sleep time across 24 hours decreases to age-appropriate levels. ${ }^{9}$

Narcolepsy treatment extends over the patient's lifetime, with the choice of treatment symptomatically driven and with reduction in EDS and cataplexy the primary therapeutic goals. ${ }^{10,11}$ However, current narcolepsy treatment guidelines were developed for adults, and while treatment of pediatric narcolepsy has generally been similar to that of adults, few drugs have been formally evaluated in children.

A key challenge for evaluating efficacy of narcolepsy therapies in children in clinical trials is the lack of appropriate measures designed for pediatric patients.

Documentation of the presence of cataplexy often relies on patient reports, but children may not adequately communicate their symptoms, may be embarrassed to report their symptoms, and may not spontaneously complain about their cataplexy. Parents may not be fully aware of the meaning or frequency of some of the cataplexy symptoms. A daily diary is generally used to monitor cataplexy attacks, but in the pediatric setting it is important for patients to recognize and understand its manifestations. As indicated in a recent literature review, ${ }^{12}$ there is no standard cataplexy diary currently.

\section{Measuring EDS}

Before considering EDS in children and adolescents, it is necessary to more generally consider "sleepiness." There is no general consensus currently on how "sleepiness" and EDS should be measured. ${ }^{13,14}$ The operational definition of EDS adopted here is "the tendency to fall asleep at times and under circumstances when the intention and expectation is to remain awake." ${ }^{13}$ The term EDS refers to unintended daytime sleep episodes, not to naps that occur after lying down purposefully. It is specifically distinguished from other tendencies or aspects of sleep habits, such as being hard to wake in the morning.

Much confusion about "sleepiness" and EDS arises because of an inadequate conceptual framework. ${ }^{13}$ For example, the currently accepted model of sleep and wakefulness does not account for the person's posture, physical and mental activities, or level of environmental stimulation. It is self-evident that we are much more likely to fall asleep when lying down than when standing up, which is attributed to differences in the somnificity of those postures; somnificity is defined as the "general characteristic of a posture, activity and situation that reflects its capacity to facilitate sleep onset in the majority of people." ${ }^{13,15}$ This concept has implications for the assessment of "sleepiness" and EDS that are not widely recognized.

A person's usual sleep propensity when in the same situation (ie, their situational sleep propensity [SSP]), whether measured objectively or subjectively, is not necessarily related to their SSP in a different situation. ${ }^{15}$ It seems that all measures of sleep propensity are partially situation specific. However, compared with people without narcolepsy, narcoleptic patients tend to have increased SSPs during most of their daily activities, which is most obvious during activities with a low somnificity, such as sitting and talking to someone. Within this conceptual framework, EDS of any cause is a manifestation of an abnormally high "average sleep propensity" (ASP) in daily life. ${ }^{13}$ However, ASP is a hypothetical construct for which there is (currently) no comparable objective measure as a gold standard.

Various objective and subjective methods have been used to measure "sleepiness" in adults, including the Multiple Sleep Latency Test (MSLT) and the Maintenance of Wakefulness Test (MWT). In the MSLT, participants are lying down, with eyes closed, and trying to fall asleep, while in the MWT they are reclining, with eyes open, and trying to remain awake. Such laboratory-based tests are very time-consuming and expensive, so it is hard to justify their routine use.

In contrast, the Epworth Sleepiness Scale (ESS) is a brief questionnaire that is inexpensive and easy to use. It measures eight different SSPs as item scores, each of which is a retrospective subjective report (rated 0-3) about the respondent's likelihood or "chances" of having fallen asleep when they were in particular situations. ${ }^{16}$ Thus, ESS item scores are based on participants' recollections of their own behavior, although these recollections are subject to reporting bias, and even to falsification, if some responses are perceived to reflect unfavorably on the respondent. The total ESS score, which is the sum of the eight item scores, gives an estimate of that person's $\mathrm{ASP}^{13}$ and can discriminate narcoleptic patients from healthy controls with sensitivity and specificity comparable with those of the MSLT or the MWT. ${ }^{17,18}$ Total ESS scores have proven to be as useful as MWT sleep latencies when assessing outcomes in the treatment of adult narcoleptics. ${ }^{19}$ 
The ESS items were selected on a priori grounds to measure the participant's propensity to doze off or fall asleep (a single concept) when engaged in a variety of different activities with different somnificities, from very high ("lying down to rest in the afternoon when circumstances permit") to low ("sitting and talking to someone"), and the differences in somnificity have been confirmed. . $^{13,20,21}$

It is important to note that ESS is not a symptom checklist for identifying situations in which the participant inadvertently falls asleep, nor is it intended to diagnose particular sleep disorders. It is intended to provide a single measure, the total ESS score, which is an estimate of the respondent's ASP. The reference range of normal ESS scores is 0-10, and scores of 11-24 represent increasing levels of EDS; $;^{18}$ the mean (standard deviation) of ESS scores in a series of 522 narcoleptic adults was $17.8(3.8) .{ }^{22}$

A recent literature review by Benmedjahed et $\mathrm{al}^{12}$ reported that there are many other questionnaires purporting to measure "sleepiness" and EDS in children and adolescents:

- One such questionnaire is the Pediatric Daytime Sleepiness Scale (PDSS), consisting of eight questions..$^{23}$ One question, "How often do you fall asleep or get drowsy during class periods?," clearly treats "sleepiness" as sleep propensity, when the intention is to remain awake. However, other questions ask how often they "have trouble getting out of bed in the morning" or "need someone to wake them in the morning," which implies that "sleepiness" is a much broader concept. Such questions do not assess "sleepiness" as a clearly defined unitary concept.

- Several surveys among adolescents have used the adult ESS without modification. ${ }^{24-26}$ They reported that most adolescents can answer the adult ESS without difficulty, presumably by ignoring the reference to alcohol and assuming that questions about traveling in a car refer to them as passengers rather than drivers. However, the adult ESS would not be suitable for younger children unless it was modified.

- Several modifications of the adult ESS have been used. Although some have involved minimal changes to the adult ESS, ${ }^{27}$ others had more substantial changes. ${ }^{27-29}$

There are problems in having several different versions of a test being used. While each version may prove to be satisfactory within its own experimental paradigm, the results cannot necessarily be compared with those from other investigations. Although other versions of the adult ESS have been cited, they have not been authorized by the developer, and the ESS is subject to copyright (@ MW Johns, 1990-1997).
The aims of the current investigation were: 1) to investigate how to appropriately identify and measure the frequency of cataplexy attacks in children and adolescents who have previously been diagnosed with narcolepsy with cataplexy (narcolepsy type 1), and 2) to optimize a provisionally modified version of the ESS for children and adolescents, called the ESS-CHAD (Figure 1). Our focus was not on the method of their initial diagnosis of narcolepsy type 1, but rather on the assessment of those cardinal symptoms that might change during treatment. Thus, our primary focus was on the development of outcome measures in the treatment of narcolepsy type 1 .

\section{Patients and methods}

The appropriateness of two pediatric narcolepsy outcomes measures, one for cataplexy and one for EDS, was evaluated by conducting face-to-face concept elicitation and cognitive interviews with pediatric narcolepsy patients and their parents or caregivers. The measure for cataplexy was a daily diary, previously used in adult clinical trials, which captured the presence and frequency of cataplexy attacks. ${ }^{30-33}$

The measure for EDS was a provisional version of the ESS-CHAD, similar to the ESS but with minor changes to be more easily understood by children.

Children and adolescents diagnosed with narcolepsy type 1 were recruited, together with one of their parents/caregivers, by sleep specialists. The four study sites were located in Norfolk, VA, USA; Washington, DC, USA; Huntsville, AL, USA; and Houston, TX, USA. The study was approved by an independent institutional review board (Copernicus Group, Durham, NC, USA) and a local ethics committee (Children's National Medical Center, Washington, DC, USA).

All patients who participated in the interviews were required to have been diagnosed with narcolepsy type 1 and were stratified into two age groups, 7- to 9-year-old children $(n=13)$ and 10- to 17-year-old adolescents $(n=16)$. The parents/caregivers of these patients were interviewed separately. The interviews were designed to capture information on how children and adolescents understand, experience, and report cataplexy attacks and daytime sleepiness so that evaluation of these symptoms in pediatric patients could be improved.

The interviews lasted approximately 1 hour and were conducted by trained interviewers using a semi-structured interview guide in the absence of a clinician (clinicians remained anonymous to interview findings). Patients were interviewed in separate rooms from his/her parents/caregivers by different interviewers. Written informed consent for participation and recording of the interviews was obtained from all 


\begin{tabular}{|c|c|}
\hline \multicolumn{2}{|l|}{$\begin{array}{c}\text { Epworth Sleepiness Scale for } \\
\text { Children and Adolescents } \\
\text { ESS (CHAD) }\end{array}$} \\
\hline Your name: & \\
\hline How old are you? __ (years) Boy? (_) or Girl? (- & k one space \\
\hline $\begin{array}{l}\text { Over the last few weeks, how likely have you be } \\
\text { or fall asleep while doing the things that are desc } \\
\text { (activities)? }\end{array}$ & d below \\
\hline $\begin{array}{l}\text { Even if you haven't done some of these things re } \\
\text { work out how they would have affected you. }\end{array}$ & tly, try to \\
\hline $\begin{array}{l}\text { Use the following scale to choose a number that } \\
\text { what has been happening to you during each ac }\end{array}$ & t describes \\
\hline $\begin{aligned} 0 & =\text { would never doze } \\
1 & =\text { slight chance of dozing } \\
2 & =\text { moderate chance of dozing } \\
3 & =\text { high chance of dozing }\end{aligned}$ & \\
\hline It is important that you answer each & tion \\
\hline Activities & $\begin{array}{l}\text { Chance } \\
\text { of dozing } \\
(0-3)\end{array}$ \\
\hline Sitting and reading & \\
\hline Sitting and watching $\mathrm{TV}_{-}$ & \\
\hline In a classroom at school during the morning & \\
\hline $\begin{array}{l}\text { As a passenger in a car for about } 30 \text { minutes } \\
\text { without a break }\end{array}$ & \\
\hline Lying down to rest in the afternoon & \\
\hline Sitting and talking to someone & \\
\hline Sitting by yourself after lunch & \\
\hline $\begin{array}{l}\text { As a passenger in a car while stopped for a few } \\
\text { minutes in the traffic }\end{array}$ & \\
\hline $\begin{array}{c}\text { Thank you } \\
\text { Copyright } \odot \text { M.W. Johns 1990, 1997, } 2013\end{array}$ & \\
\hline
\end{tabular}

Figure I Provisional version of the ESS-CHAD.

Abbreviation: ESS-CHAD, Epworth Sleepiness Scale for Children and Adolescents.

parents/caregivers of the patients. Informed assent was obtained from the adolescent patients, but 7-9-year-old children were considered too young for that.

Interviews were in two parts, and participants were encouraged to speak freely and spontaneously during the interview, with only minimal and strategic use of probing questions. Part 1 was for concept elicitation - spontaneously eliciting the patient's experience and understanding of the concepts of daytime sleepiness and cataplexy. Part 2 was for cognitive debriefing - assessing the participants' understanding and comprehension of the measures, as well as their relevance and appropriateness for a pediatric population. Participants were asked to "think aloud" while providing their response to each item and to indicate what they were thinking as they answered and why they chose a particular response option. This method represents a relatively standardized approach to cognitive debriefing and reduces the chance of the interviewer introducing bias into the responses. This 
method also encourages the participants to explain their rationale behind each answer and to identify how a particular item may be problematic. ${ }^{34}$

Following each interview, the recordings were transcribed verbatim, and all identifying characteristics were removed from the transcripts to ensure confidentiality and anonymity. Analysis of the concept elicitation part was performed using software designed for qualitative analysis (Atlas.ti 7.0; Scientific Software Development GmbH, Berlin, Germany). ${ }^{35}$ To ensure that all relevant concepts were captured, "concept saturation" was considered complete "when no new relevant or important information emerges and collecting additional data will not add to the understanding of how patients perceive the concept of interest." ${ }^{36}$ Concept saturation was assessed separately for children, adolescents, and parents/caregivers using codes related to the symptoms of narcolepsy, symptoms of cataplexy, narcolepsy characteristics/settings, and triggers of cataplexy. For the cognitive debriefing part, a line-by-line approach was used to document the participant's understanding of the instructions, questions, response options, and recall period.

The provisional ESS-CHAD was given to all participants to complete, with or without help from a parent/caregiver. This questionnaire was very similar to the standardized adult ESS but with the following minor changes: the recall period was changed from "in recent times" to "over the last few weeks"; question 2 was changed from "watching TV" to "sitting and watching TV"; question 3 was changed from "sitting inactive in a public place (eg, a theater or meeting)" to "in a classroom at school during the morning"; question 4 was changed from "as a passenger in a car for an hour without a break" to "as a passenger in a car for about 30 minutes without a break"; question 8 was changed from "in a car while stopped for a few minutes in the traffic" to "as a passenger in a car while stopped for a few minutes in the traffic." These changes were made to clarify and more accurately describe the activities in words that would be more easily understood by children, but without changing the nature of the questions, the activities described in them, or their relative somnificities. The provisional ESSCHAD had not been widely tested or optimized, with feedback from children, especially those with narcolepsy type 1 .

\section{Results}

\section{Participants}

A total of 58 participants (29 parent-patient pairs) were interviewed. The patients were approximately evenly distributed by sex ( $48.3 \%$ female) and age group ( $44.8 \%$ children, $55.2 \%$ adolescents), and most were black/African American (65.6\%; Table 1).
Table I Demographic characteristics of the pediatric patients who participated in cognitive debriefing interviews $(n=29)$

\begin{tabular}{ll}
\hline Variable & Value \\
\hline Sex, $\mathrm{n}(\%)$ & \\
$\quad$ Male & $15(51.7)$ \\
Female & $14(48.3)$ \\
Age, years, mean (SD) & $11.6(3.5)$ \\
Age group, $\mathrm{n}(\%)$ & \\
7-9 years & $13(44.8)$ \\
I0-17 years & $16(55.2)$ \\
Race, $\mathrm{n}(\%)$ & \\
Black/African American & $19(65.6)$ \\
White & $8(27.6)$ \\
Others & $2(6.9)$ \\
\hline
\end{tabular}

\section{Concept elicitation}

Concept saturation was reached for cataplexy symptoms and triggers, indicating that all relevant concepts were adequately captured. Among the main cataplexy symptoms (Table 2), lower-limb weakness was consistently the most frequently endorsed symptom across the three interview groups and had the highest recognition among children (84.6\%). Body weakness and upper-limb weakness were also endorsed by substantial proportions of patients, with body weakness having higher recognition among patients (46.2-56.3\%) than among parents/caregivers (37.9\%), and upper-limb weakness having greatest recognition among the parents/caregivers $(44.8 \%$ versus 30.8-31.3\%). Parents/caregivers also provided greater endorsement of facial weakness (34.5\% versus $7.7-12.5 \%$ for patients). Pain after an attack had generally low recognition (15.4-18.8\% in patients, $10.3 \%$ in parents/caregivers), and dizziness was endorsed only by adolescents (18.8\%; Table 2$)$.

Laughter was the most frequently endorsed cataplexy trigger across the three subject groups (53.8-68.8\%), with the highest recognition among adolescents (Table 2). The next most frequently endorsed trigger was anger among adolescents $(25.0 \%)$ and parents/caregivers $(27.6 \%)$, followed by excitement, which was similarly endorsed by children $(23.1 \%)$ and parents/caregivers $(24.1 \%)$, but less frequently by adolescents $(6.3 \%)$. Other cataplexy triggers had lower $(\leq 20 \%)$ rates of endorsement across the three groups. Situations in which cataplexy occurred also had low $(\leq 10 \%)$ rates of endorsement, except for walking/running (37.5\%) and in the morning (12.5\%) among adolescents.

The most frequently endorsed symptoms of narcolepsy were related to sleepiness (Table 3). They included excessive sleeping, tiredness/sleepiness, and difficulty waking up, all of which were more frequently endorsed by parents/caregivers than by the adolescent patients. Vivid dreams/hallucinations/ sleep paralysis was endorsed by substantial proportions of 
Table 2 Main concepts of cataplexy endorsed by $\geq 2$ participants in any interview group

\begin{tabular}{|c|c|c|c|}
\hline \multirow[t]{2}{*}{ Concept } & \multicolumn{3}{|c|}{ Participants endorsing concept, n (\%) } \\
\hline & $\begin{array}{l}\text { Children, 7-9 years } \\
(n=13)\end{array}$ & $\begin{array}{l}\text { Adolescents, } 10-17 \text { years } \\
(\mathrm{n}=16)\end{array}$ & $\begin{array}{l}\text { Parents/caregivers } \\
(\mathrm{n}=29)\end{array}$ \\
\hline \multicolumn{4}{|l|}{ Manifestations } \\
\hline Weakness, lower limb (eg, falling down, leaning over) & II (84.6) & $10(62.5)$ & $23(79.3)$ \\
\hline Weakness, body (overall sensation) & $6(46.2)$ & $9(56.3)$ & II (37.9) \\
\hline Weakness, upper limb (eg, arms flailing/dropping to side) & $4(30.8)$ & $5(3 \mid .3)$ & $13(44.8)$ \\
\hline Weakness, neck (eg, head slumping) & - & $5(3 \mid .3)$ & $12(41.4)$ \\
\hline $\begin{array}{l}\text { Weakness, face (eg, facial tick, eyes rolling, jaw dropping, } \\
\text { tongue sticking out) }\end{array}$ & I (7.7) & $2(12.5)$ & $10(34.5)$ \\
\hline Pain (eg, headache, leg hurting) after an attack & $2(15.4)$ & $3(18.8)$ & $3(10.3)$ \\
\hline Dizziness & - & $3(18.8)$ & - \\
\hline \multicolumn{4}{|l|}{ Triggers } \\
\hline Laughter & $7(53.8)$ & II (68.8) & $16(55.2)$ \\
\hline Angry & - & $4(25.0)$ & $8(27.6)$ \\
\hline Excited & $3(23.1)$ & I (6.3) & $7(24.1)$ \\
\hline Scared & $2(15.4)$ & $2(12.5)$ & $5(17.2)$ \\
\hline Upset & - & $3(18.8)$ & $4(13.8)$ \\
\hline At school & $2(15.4)$ & $2(12.5)$ & $2(6.9)$ \\
\hline At home & $2(15.4)$ & $2(12.5)$ & - \\
\hline Nervous & - & $2(12.5)$ & $2(6.9)$ \\
\hline Crying & - & - & $3(10.3)$ \\
\hline Happy & $2(15.4)$ & - & I (3.4) \\
\hline \multicolumn{4}{|l|}{ Situations } \\
\hline Walking/running & I (7.7) & $6(37.5)$ & $2(6.9)$ \\
\hline In the morning & - & $2(12.5)$ & $2(6.9)$ \\
\hline In the evening & - & I (6.3) & $2(6.9)$ \\
\hline While playing & - & - & $3(10.3)$ \\
\hline When tired & I (7.7) & - & $2(6.9)$ \\
\hline
\end{tabular}

children (53.8\%) and parents/caregivers (48.3\%), but fewer adolescents $(25.0 \%)$.

There was high endorsement of sleepiness across all three interview groups for the setting of "in a car," "at school," and "when watching TV/Internet/videos/movies" (Table 3). Other settings showed variable rates of endorsement among the interview groups; for example, there was greater endorsement of "when inactive" by parents/caregivers $(55.2 \%)$ than by children (7.7\%) and adolescents (37.5\%). Concept saturation was reached in the group of parents/caregivers. However, saturation was not reached as new concepts emerged during last interviews among children ("after physical activity", "when quiet", and "when watching sports in person") and adolescents ("when quiet" and "when working on a computer"), although these overlapped with other concepts previously reported.

\section{Cognitive debriefing}

In evaluating the appropriateness of the cataplexy diary, approximately half of the children $(53.8 \%)$ had some reading difficulties, and more than one-third of adolescents (37.5\%) had difficulties understanding the instructions and needed to reread them or get clarification. Despite these difficulties, the term "cataplexy" was understood by approximately half of the children $(53.8 \%)$ and all the adolescents, except for one adolescent (11 years old) who did not know or could not figure out that term. In general, there were no major issues with the understanding of "recall," which was interpreted by children as "today" and "since waking up," but two adolescents expressed difficulty with remembering. The suggestion that their child would be better at answering was made by four parents. The final version of the cataplexy diary is shown in Figure 2.

Difficulty in comprehension was also an issue for the provisional ESS-CHAD in several children. One 9-year-old child did not understand the instructions at all, one 9-yearold misunderstood the questions, and four children (two 8-year-olds and two 9-year-olds) needed help to understand the questionnaire. There was also varied understanding of the phrasing for the recall period ("over the last few weeks"). Use of the term "tick" in the response instructions was confusing, with additional wording problems related to the terms "moderate" and "dozing off."

Although there was greater overall understanding of the questionnaire among adolescents, there were the same 
Table 3 Main concepts of symptoms and settings of narcolepsy endorsed by $\geq 2$ participants in any interview group

\begin{tabular}{|c|c|c|c|}
\hline \multirow[t]{2}{*}{ Concept } & \multicolumn{3}{|c|}{ Participants endorsing concept, $\mathbf{n}(\%)$} \\
\hline & $\begin{array}{l}\text { Children, } 7-9 \text { years } \\
(n=13)\end{array}$ & $\begin{array}{l}\text { Adolescents, } 10-17 \text { years } \\
(n=16)\end{array}$ & $\begin{array}{l}\text { Parents/caregivers } \\
(\mathrm{n}=29)\end{array}$ \\
\hline \multicolumn{4}{|l|}{ Symptoms } \\
\hline Excessive sleeping & $10(76.9)$ & $12(75.0)$ & $29(100)$ \\
\hline Tiredness/sleepiness & II (84.6) & II (68.8) & $22(75.9)$ \\
\hline Difficulty waking up & $5(38.5)$ & $9(56.3)$ & I7 (58.6) \\
\hline Vivid dreams/hallucinations/sleep paralysis & $7(53.8)$ & $4(25.0)$ & $14(48.3)$ \\
\hline Difficulty falling/staying asleep at night & $5(38.5)$ & $4(25.0)$ & $15(5 \mid .7)$ \\
\hline Eyes closing/drooping & $2(15.4)$ & $6(37.5)$ & $8(27.6)$ \\
\hline Sleepwalking/talking while asleep & $2(15.4)$ & I (6.3) & $10(34.5)$ \\
\hline Low energy/weakness & - & $4(25.0)$ & $8(27.6)$ \\
\hline Difficulty paying attention/zoning out & - & $2(12.5)$ & $3(10.3)$ \\
\hline Eating while asleep/in the middle of the night & I (7.7) & - & $3(10.3)$ \\
\hline Dizziness & I (7.7) & $2(12.5)$ & - \\
\hline \multicolumn{4}{|l|}{ Settings } \\
\hline In a car & $10(76.9)$ & $14(87.5)$ & $27(93.1)$ \\
\hline At school & $10(76.9)$ & $14(87.5)$ & $20(69.0)$ \\
\hline When watching TV/Internet/videos/movies & $7(53.8)$ & $12(75.0)$ & $21(72.4)$ \\
\hline When inactive & I (7.7) & $6(37.5)$ & $16(55.2)$ \\
\hline At home & $2(15.4)$ & $8(50.0)$ & $12(41.4)$ \\
\hline When sitting down & $2(15.4)$ & $6(37.5)$ & II (37.9) \\
\hline While doing homework & $4(30.8)$ & $6(37.5)$ & $8(27.6)$ \\
\hline When reading a book & I (7.7) & $5(31.3)$ & II (37.9) \\
\hline When eating & $2(15.4)$ & - & $10(34.5)$ \\
\hline During a conversation & $\mathrm{I}(7.7)$ & $2(12.5)$ & $8(27.6)$ \\
\hline At other's home & I (7.7) & $3(18.8)$ & $3(10.3)$ \\
\hline When waking up & $3(23.1)$ & $I(6.3)$ & $3(10.3)$ \\
\hline When playing sports/training & $\mathrm{I}(7.7)$ & $3(18.8)$ & $2(6.9)$ \\
\hline When playing video games & I (7.7) & $2(12.5)$ & $3(10.3)$ \\
\hline After eating/feeling full & $2(15.4)$ & $2(12.5)$ & $2(6.9)$ \\
\hline Playing with friends & - & - & $5(I 7.2)$ \\
\hline Showering/bathing & I (7.7) & I (6.3) & $3(10.3)$ \\
\hline Taking a test & - & $3(18.8)$ & $2(6.9)$ \\
\hline In public transportation & I (7.7) & I (6.3) & $2(6.9)$ \\
\hline Lying down & - & $3(18.8)$ & I (3.4) \\
\hline After HINI vaccination & - & - & $2(6.9)$ \\
\hline Church & - & - & $2(6.9)$ \\
\hline After a long day & - & $2(12.5)$ & - \\
\hline Watching a show & - & - & $2(6.9)$ \\
\hline
\end{tabular}

wording problems that were identified by the children, as well as similar problems with understanding of the recall period. Parents/caregivers had no issues understanding the instructions, but they nevertheless expressed the same opinion regarding the lack of clarity for the recall period that was mentioned by patients.

Some of these issues arose because the provisional ESSCHAD was developed in English for Australia and needed to be changed for American use. Others issues were more general, such as the specification of the recall period, use of the term "dozing," and the inclusion of one activity/situation (question 8) that was considered to be too far from the everyday experience of children. These matters were addressed in the final version of the ESS-CHAD as follows (Figure 3): the instructions were changed, replacing "try to work out how they would have affected you" with "try to imagine how they would have affected you." The phrase "doze off or fall asleep" was replaced with "fall asleep." The recall period was described more specifically as "over the last month," but to meet specific research requirements, another alternative was proposed, ie, "since your last study visit," if the visit was at least 1 week ago. The original question 8 ("As a passenger in a car while stopped for a few minutes in the traffic") was replaced with a new question, "sitting and eating a meal," which has a low somnificity, similar to the original question, but which refers to an activity occurring every day rather than as a rare event. 


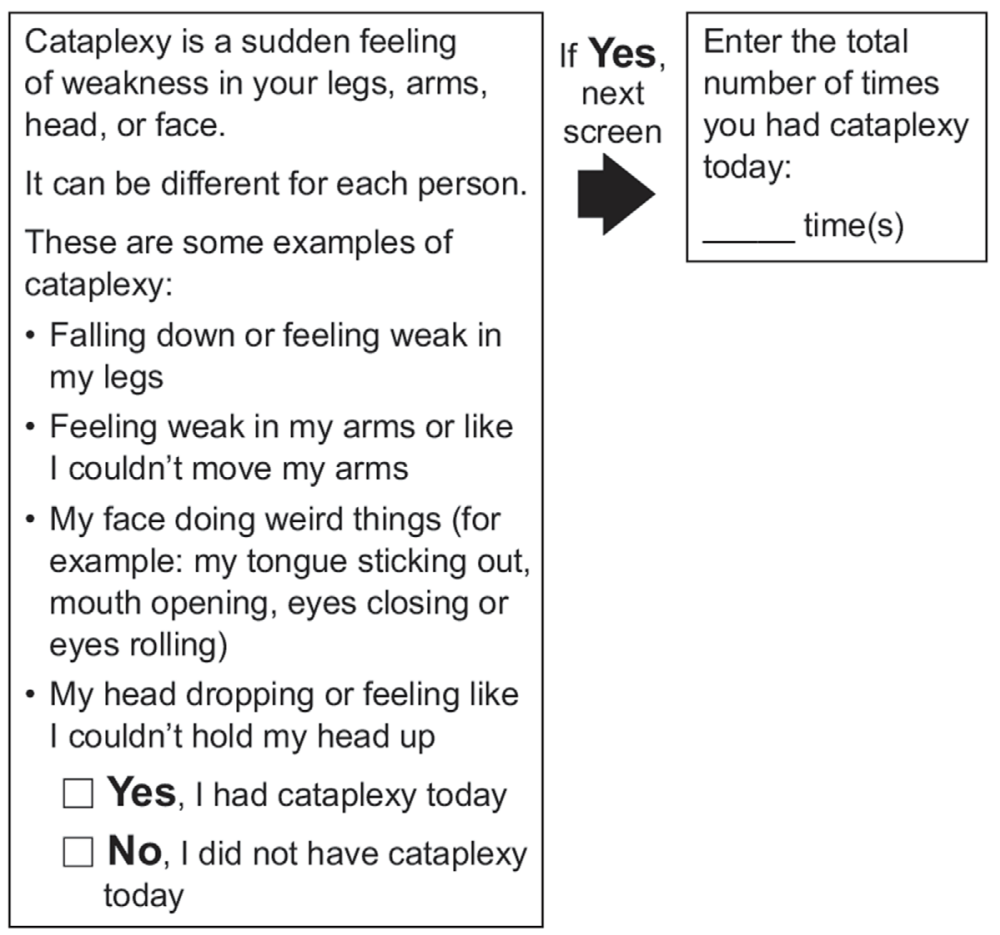

Figure 2 Final version of the electronic cataplexy daily diary.

\section{Discussion}

This study identified limitations of the initially proposed measures of cataplexy and EDS in children and adolescents who have narcolepsy type 1 . With information elicited during cognitive debriefing interviews, these limitations have been addressed and newly adapted measures have been proposed. These results are based on a small population, including younger school-aged children as well as adolescents with narcolepsy type 1, who were primarily black/African American or white, and their parents and caregivers from a broad US geographic area.

Subtle differences were noted between the symptoms described by the patients and their parents/caregivers. This provided alternative but complementary perspectives on how cataplexy and narcolepsy are observed and reported. Parents may not recognize cataplexy symptoms/triggers as well as children do, but parents generally had greater recognition of excessive sleepiness and the settings where children/adolescents fall asleep. Although a variety of such settings were identified, high endorsement across the interview groups was observed for only a few of the settings, with some of these settings consistent with those already included in the ESS (ie, reading, watching TV, and being a passenger in a car). School was uniformly endorsed as one of the most frequent settings for narcolepsy symptom manifestation. These differences in responses that were observed for both cataplexy and sleepiness additionally suggest the utility of taking a case history from children and their parents/caregivers.

Since some patients had difficulty reading or understanding the cataplexy diary, modifications were made by providing a definition and examples of cataplexy using child-friendly terminology. A quantitative question was also incorporated to determine daily frequency of attacks, and the questionnaire was standardized for evening administration based on self-completion by patients aged $\geq 9$ years; parent assistance should still be considered for these patients and is recommended for those aged $<9$ years.

Similarly, with the ESS-CHAD, some patients had difficulty understanding the instructions and several of the questions in the provisional questionnaire. Based on these difficulties, child-friendly wording was used in the final versions of the ESS-CHAD, and items were either adapted or, in one case, replaced by one that more closely reflected the daily activities of children and adolescents. Since recall was reported as an issue across the interview groups, it was more clearly defined, and the recall period was specifically stated as "over the past month." Broderick et al ${ }^{37}$ investigated the effects of different recall periods on ESS scores in adults. They found that a recall period of 28 days was satisfactory. However, in research protocols, such recall periods may overlap when used for frequent evaluation in clinical trials. This study and a study reported by van der Heide et a ${ }^{19}$ have 


\begin{tabular}{|c|c|}
\hline \multicolumn{2}{|l|}{$\begin{array}{l}\text { Epworth Sleepiness Scale for } \\
\text { Children and Adolescents }\end{array}$} \\
\hline \multicolumn{2}{|l|}{ ESS-CHAD } \\
\hline \multicolumn{2}{|c|}{ _Today's date: } \\
\hline \multicolumn{2}{|c|}{ How old are you? __ (years) Boy? (_) or Girl? (_) check one space } \\
\hline \multicolumn{2}{|c|}{$\begin{array}{l}\text { Over the past month, how likely have you been to fall asleep } \\
\text { while doing the things that are described below (activities)? }\end{array}$} \\
\hline \multicolumn{2}{|c|}{$\begin{array}{l}\text { Even if you haven't done some of these things in the past } \\
\text { month, try to imagine how they would have affected you. }\end{array}$} \\
\hline \multicolumn{2}{|c|}{$\begin{array}{l}\text { Use the following scale to choose one number that best de- } \\
\text { scribes what has been happening to you during each activity } \\
\text { over the past month. Write that number in the box below. }\end{array}$} \\
\hline $\begin{array}{l}0=\text { would never fall asleep } \\
1=\text { slight chance of falling asleep } \\
2=\text { moderate chance of falling asle } \\
3=\text { high chance of falling asleep }\end{array}$ & \\
\hline \multicolumn{2}{|c|}{ It is important that you answer every question as best you car } \\
\hline Activities & $\begin{array}{l}\text { Chance of } \\
\text { falling asleep } \\
(0-3)\end{array}$ \\
\hline Sitting and reading & \\
\hline Sitting and watching TV or a video & \\
\hline Sitting in a classroom at school during the morning & \\
\hline $\begin{array}{l}\text { Sitting and riding in a car or a bus for about } \\
\text { half an hour. }\end{array}$ & \\
\hline Lying down to rest or nap in the afternoon & \\
\hline Sitting and talking to someone & \\
\hline Sitting quietly by yourself after lunch & \\
\hline Sitting and eating a meal & \\
\hline $\begin{array}{l}\text { Thank you } \\
\text { Copyright } \odot \text { MW Johns, 1990-2015 }\end{array}$ & \\
\hline
\end{tabular}

Figure 3 Final general version (A) and an alternative (research) version (B) of ESS-CHAD.

Abbreviation: ESS-CHAD, Epworth Sleepiness Scale for Children and Adolescents.

identified the validity of the ESS when the assessment period was 1 week. An alternative (research) version was therefore proposed with a recall period "since your last study visit," provided that it was at least 1 week ago.

It was not our intention to develop a new "sleepiness" questionnaire de novo, as others have attempted in the past. Rather, it was to use the well-established and well-validated adult ESS as the basis for a modified and authorized version for use among children and adolescents (ESS-CHAD). Its questions were to be very similar to those of the adult ESS, chosen by the same method, and with similar somnificities. The provisional version of the ESS-CHAD was found to present some difficulties with comprehension, mainly for younger children, and these were addressed by minor changes to the

\section{B) ESS-CHAD Research Version}

Since your last study visit, how likely have you been to fall asleep while doing the things that are described below (activities)? Please check the box that describes you best since your last study visit.

Even if you haven't done some of these things since your last study visit, try to imagine how they would have affected you. It is important that you answer every question as best you can.

1. Sitting and reading

$\square$ Would never fall asleep

$\square$ Slight chance of falling asleep

$\square$ Moderate chance of falling asleep

$\square$ High chance of falling asleep

2. Sitting and watching TV or a video

$\square$ Would never fall asleep

$\square$ Slight chance of falling asleep

$\square$ Moderate chance of falling asleep

$\square$ High chance of falling asleep

3. Sitting quietly in a classroom at school during the morning $\square$ Would never fall asleep

$\square$ Slight chance of falling asleep

$\square$ Moderate chance of falling asleep

$\square$ High chance of falling asleep

4. Sitting and riding in a car or a bus for about half an hour

$\square$ Would never fall asleep

$\square$ Slight chance of falling asleep

$\square$ Moderate chance of falling asleep

$\square$ High chance of falling asleep

5. Lying down to rest or nap in the afternoon

$\square$ Would never fall asleep

$\square$ Slight chance of falling asleep

$\square$ Moderate chance of falling asleep

$\square$ High chance of falling asleep

6. Sitting and talking to someone

$\square$ Would never fall asleep

$\square$ Slight chance of falling asleep

$\square$ Moderate chance of falling asleep

$\square$ High chance of falling asleep

7. Sitting quietly by yourself after lunch

$\square$ Would never fall asleep

$\square$ Slight chance of falling asleep

$\square$ Moderate chance of falling asleep

$\square$ High chance of falling asleep

8. Sitting and eating a meal

$\square$ Would never fall asleep

$\square$ Slight chance of falling asleep

$\square$ Moderate chance of falling asleep

$\square$ High chance of falling asleep wording in the final version. Nevertheless, it seems likely that most children aged $<9$ years require parental assistance to answer the ESS-CHAD. The format of answers to the questions in the ESS-CHAD, shown in Figure 3 as 0-3, can be changed for use with electronic scoring, as is sometimes performed with the adult ESS.

If the ESS-CHAD was to be used more generally in the future, it could overcome the problem of having many different versions of a questionnaire, all of which purport to measure the same thing but which are unauthorized in a copyright sense, and which have results that may not be comparable between different investigations. Use of the ESSCHAD would permit assessments of "sleepiness" and of EDS across a wider range of ages than is possible with the adult 
ESS alone. The ESS-CHAD has recently been shown to have good psychometric properties when used among adolescents, in terms of its validity, unitary structure, and reliability. ${ }^{38}$ The cataplexy diary and the modified version of the ESS-CHAD are being used as outcome measures in a Phase III, placebocontrolled clinical trial of sodium oxybate in children and adolescents with narcolepsy (NCT02221869).

Limitations of this study include the small sample size, and a sample that may not necessarily be broadly representative of pediatric narcolepsy patients due to some limitations in racial and ethnic diversity and the fact that the study was conducted in only one language, English. However, there is no clinical rationale for believing that the signs and symptoms of cataplexy and narcolepsy would differ because of these factors.

\section{Conclusion}

A daily diary for the assessment of cataplexy and the ESSCHAD questionnaire for the assessment of EDS were modified, so these instruments could be administered to children and adolescents with narcolepsy. Further studies of the psychometric properties of these two instruments, including their normative values and their responsiveness to treatments of narcolepsy type 1 , are needed. These instruments are currently being used in a Phase III, placebo-controlled clinical trial of sodium oxybate in children and adolescents with narcolepsy.

\section{Acknowledgments}

The authors gratefully acknowledge the contributions of the investigators and the patients and families who participated in the study. This study was funded by Jazz Pharmaceuticals. Under the direction of the authors, E Jay Bienen, PhD, of the Curry Rockefeller Group, LLC (CRG), provided medical writing assistance for this publication. Editorial assistance in formatting, proofreading, copy editing, and fact checking was also provided by CRG. Jazz Pharmaceuticals provided funding to $\mathrm{CRG}$ for medical writing and editorial support of this manuscript.

\section{Disclosure}

Dr Y Grace Wang is an employee of Jazz Pharmaceuticals, who in the course of this employment has received stock options exercisable for, and other stock awards of, ordinary shares of Jazz Pharmaceuticals. Dr Khadra Benmedjahed and Dr Jérémy Lambert are employees of Mapi, a consulting company commissioned by Jazz Pharmaceuticals for this study. Dr Christopher J Evans and Mr Steve Hwang are employees of Endpoint Outcomes, a consulting company commissioned by Jazz Pharmaceuticals for this study. Dr Jed Black is a part-time employee of Jazz Pharmaceuticals and holds stock in Jazz Pharmaceuticals plc. Dr Murray W Johns owns the copyright to the ESS and has received license fees from corporations and government agencies; the ESS-CHAD was used in this study with permission and cooperation, and without financial considerations, by Jazz Pharmaceuticals. The authors report no other conflicts of interest in this work.

\section{References}

1. Ohayon MM, Ferini-Strambi L, Plazzi G, Smirne S, Castronovo V. How age influences the expression of narcolepsy. JPsychosom Res. 2005;59(6): 399-405.

2. Okun ML, Lin L, Pelin Z, Hong S, Mignot E. Clinical aspects of narcolepsy-cataplexy across ethnic groups. Sleep. 2002;25(1):27-35.

3. Aran A, Einen M, Lin L, Plazzi G, Nishino S, Mignot E. Clinical and therapeutic aspects of childhood narcolepsy-cataplexy: a retrospective study of 51 children. Sleep. 2010;33(11):1457-1464.

4. Thorpy MJ, Krieger AC. Delayed diagnosis of narcolepsy: characterization and impact. Sleep Med. 2014;15(5):502-507.

5. Carter LP, Acebo C, Kim A. Patients' journeys to a narcolepsy diagnosis: a physician survey and retrospective chart review. Postgrad Med. 2014;126(3):216-224.

6. American Academy of Sleep Medicine. The International Classification of Sleep Disorders - Third Edition (ICSD-3). Darien, IL: American Academy of Sleep Medicine; 2014.

7. National Institute of Neurological Disorders and Stroke [webpage on the Internet]. Narcolepsy Fact Sheet. 2017. NIH Publication 13-1637. Available from: http://www.ninds.nih.gov/disorders/narcolepsy/ detail_narcolepsy.htm\#241213201. Accessed February 10, 2017.

8. Plazzi G, Pizza F, Palaia V, et al. Complex movement disorders at disease onset in childhood narcolepsy with cataplexy. Brain. 2011;134(pt 12):3477-3489.

9. Pizza F, Franceschini C, Peltola H, et al. Clinical and polysomnographic course of childhood narcolepsy with cataplexy. Brain. 2013;136(pt 12):3787-3795.

10. Billiard M, Bassetti C, Dauvilliers Y, et al. EFNS guidelines on management of narcolepsy. Eur J Neurol. 2006;13(10):1035-1048.

11. Morgenthaler TI, Kapur VK, Brown T, et al. Practice parameters for the treatment of narcolepsy and other hypersomnias of central origin. Sleep. 2007;30(12):1705-1711.

12. Benmedjahed K, Wang YG, Lambert J, et al. Assessing sleepiness and cataplexy in children and adolescents with narcolepsy: a review of current patient-reported measures. Sleep Med. 2017;32:143-149.

13. Johns MW. A new perspective on sleepiness. Sleep Biol Rhythm. 2010;8:170-179.

14. Mayer G, Lammers GJ. The MSLT: more objections than benefits as a diagnostic gold standard? [editorial]. Sleep. 2014;37(6):1027-1028.

15. Johns MW. Sleep propensity varies with behaviour and the situation in which it is measured: the concept of somnificity. J Sleep Res. 2002;11(1):61-67.

16. Johns MW. A new method for measuring daytime sleepiness: the Epworth Sleepiness Scale. Sleep. 1991;14(6):540-545.

17. Parkes JD, Chen SY, Clift SJ, Dahlitz MJ, Dunn G. The clinical diagnosis of the narcoleptic syndrome. J Sleep Res. 1998;7(1):41-52.

18. Johns MW. Sensitivity and specificity of the Multiple Sleep Latency Test (MSLT), the maintenance of wakefulness test and the Epworth Sleepiness Scale: failure of the MSLT as a gold standard. J Sleep Res. 2000;9(1):5-11. 
19. van der Heide A, van Schie MK, Lammers GJ, et al. Comparing treatment effect measurements in narcolepsy: the sustained attention to response task, Epworth Sleepiness Scale and Maintenance of Wakefulness Test. Sleep. 2015;38(7):1051-1058.

20. Ulander M, Arestedt K, Svanborg E, Johansson P, Brostrom A. The fairness of the Epworth Sleepiness Scale: two approaches to differential item functioning. Sleep Breath. 2013;17(1):157-165.

21. Sargento P, Perea V, Ladera V, Lopes P, Oliveira J. The Epworth Sleepiness Scale in Portuguese adults: from classical measurement theory to Rasch model analysis. Sleep Breath. 2015;19(2):693-701.

22. Sangal R, Mitler MM, Sangal JAM. US modafinil in narcolepsy multicentre study group. MSLT, MWT and ESS, indices of sleepiness in 522 drug-free patients with narcolepsy. Sleep Res. 1997;26:492.

23. Drake C, Nickel C, Burduvali E, Roth T, Jefferson C, Pietro B. The pediatric daytime sleepiness scale (PDSS): sleep habits and school outcomes in middle-school children. Sleep. 2003;26(4):455-458.

24. Chung KF, Cheung MM. Sleep-wake patterns and sleep disturbance among Hong Kong Chinese adolescents. Sleep. 2008;31(2): 185-194

25. Gibson ES, Powles AC, Thabane L, et al. "Sleepiness" is serious in adolescence: two surveys of 3235 Canadian students. BMC Public Health. 2006;6:116.

26. Hagemeister D, Damaraju S, Damaragu A, et al. Reliability of Epworth Sleepiness Scale to predict OSA among adolescent children [abstract]. Chest. 2011;140:Abs395A.

27. Snow A, Gozal E, Malhotra A, et al. Severe hypersomnolence after pituitary/hypothalamic surgery in adolescents: clinical characteristics and potential mechanisms. Pediatrics. 2002;110(6):e74

28. Anderson B, Storfer-Isser A, Taylor HG, Rosen CL, Redline S. Associations of executive function with sleepiness and sleep duration in adolescents. Pediatrics. 2009;123(4):e701-e707.
29. Campbell IG, Higgins LM, Trinidad JM, Richardson P, Feinberg I. The increase in longitudinally measured sleepiness across adolescence is related to the maturational decline in low-frequency EEG power. Sleep. 2007;30(12):1677-1687.

30. The US Xyrem Multi-Center Study Group. A randomized, double blind, placebo-controlled multicenter trial comparing the effects of three doses of orally administered sodium oxybate with placebo for the treatment of narcolepsy. Sleep. 2002;25:42-49.

31. U.S. Xyrem Multicenter Study Group. A 12-month, open-label, multicenter extension trial of orally administered sodium oxybate for the treatment of narcolepsy. Sleep. 2003;26(1):31-35.

32. U.S. Xyrem Multicenter Study Group. Sodium oxybate demonstrates long-term efficacy for the treatment of cataplexy in patients with narcolepsy. Sleep Med. 2004;5(2):119-123.

33. Xyrem International Study Group. Further evidence supporting the use of sodium oxybate for the treatment of cataplexy: a double-blind, placebocontrolled study in 228 patients. Sleep Med. 2005;6(5):415-421.

34. Willis GB. Cognitive Interviewing: A Tool for Improving Questionnaire Design. Thousand Oaks, CA: SAGE Publishers; 2005.

35. Murh T. User's Manual for Atlas.Ti 6.0. Berlin: Scientific Software Development; 2004.

36. Food and Drug Administration. Guidance for Industry. Patient-Reported Outcome Measures: Use in Medical Product Development to Support Labeling Claims. 2009. Available from: http://www.fda.gov/downloads/ Drugs/Guidances/UCM193282.pdf. Accessed February 10, 2017.

37. Broderick JE, Junghaenel DU, Schneider S, Pilosi JJ, Stone AA. Pittsburgh and Epworth sleep scale items: accuracy of ratings across different reporting periods. Behav Sleep Med. 2013;11(3):173-188.

38. Janssen KC, Phillipson S, O'Connor J, Johns MW. Validation of the Epworth Sleepiness Scale for children and adolescents using Rasch analysis. Sleep Med. 2017;33:30-35.
Nature and Science of Sleep

\section{Publish your work in this journal}

Nature and Science of Sleep is an international, peer-reviewed, open access journal covering all aspects of sleep science and sleep medicine, including the neurophysiology and functions of sleep, the genetics of sleep, sleep and society, biological rhythms, dreaming, sleep disorders and therapy, and strategies to optimize healthy sleep. The manuscript

\section{Dovepress}

management system is completely online and includes a very quick and fair peer-review system, which is all easy to use. Visit http://www dovepress.com/testimonials.php to read real quotes from published authors. 